\title{
LER ARISTÓFANES?
}

\author{
Daisi Malhadas* \\ Maria Celeste Consolin Dezotti*
}

\begin{abstract}
MALHADAS, D.; DEZOTTI, M.C.C. Ler Aristófanes? Rev. do Museu de Arqueologia e Etnologia, São Paulo, 14: 3-8, 2004.
\end{abstract}

RESUMO: O objetivo deste estudo é discutir, à luz da Poética de Aristóteles e de estudos de semiologia teatral, a possibilidade de leitura da comédia antiga do mesmo modo como se lê a tragédia. A questão colocada é: será que a comédia de Aristófanes pode, como a tragédia, atingir seu fim apenas com a leitura? Tudo indica que o poder da comédia depende da performance.

\section{UNITERMOS: Aristófanes - Comédia - Leitura - Performance}

Ao tratar dos recursos cômicos nas comédias de Aristófanes, Gilda Reale Starzynski (1967: 42) afirma:

"Muitas vezes se tem condenado a comédia antiga como coisa fora da moda, digna apenas dos Museus ou das empoeiradas bibliotecas dos eruditos. Em resumo, uma obra de leitura tediosa, que só pode ser bem compreendida por especialistas, senhores de indispensáveis conhecimentos de filosofia e de história".

Essa passagem mereceu da própria autora (Starzynski id., ibid.) a nota que aqui vai transcrita:

"Todavia contrariando essa idéia de que a comédia antiga é coisa morta, podemos verificar, com prazer, que as peças de Aristófanes ainda hoje podem arrancar aplausos e admiração. Há dois ou três anos a Lisistrata consistia um autêntico sucesso de bilheteria na
Alemanha Ocidental, e ainda agora, em Roma, no verão de 1962, a Assembléia das Mulheres atraiu tão numeroso público que não pôde ficar restrita ao ambiente fechado das salas de espetáculos, sendo levada para os imensos teatros ao ar livre, como o Estádio de Diocleciano, onde, em várias representações, obteve êxito invulgar".

Convém dessa passagem e de sua nota destacar duas considerações:

- a comédia antiga seria constituída por "obra de leitura tediosa";

- "as peças de Aristófanes ainda hoje podem arrancar aplausos..."

Essas considerações apontam para duas realidades: a da leitura de teatro e a da encenação; essas realidades exigem que se reflita com alguns estudiosos de teatro, a começar por Aristóteles.

Pode-se afirmar que, como a tragédia (Poética, 49b 24-27), a comédia é a representação ${ }^{1}$ de
(1) Preferimos traduzir mimesis por representação, apoiando-nos na reflexão de Dupont-Roc e Lallot (1980: 20). 
uma ação. Sem hesitar pode-se continuar o paralelo, observando-se que ambas empregam para representar os mesmos meios e o mesmo modo. Ambas empregam dois meios: elocução (lexis), a composição em metro, e melopéia (melopoía), o canto (Poética, 49b 29, 33); em ambas, esses meios se alternam nas partes constitutivas (Idem 47b 28). O modo é, conforme uma tradução literal, "de pessoas agindo (diónton) e não por narrativa (di'apangelias)" (Idem 49b 26). Trata-se, portanto, de um modo de representação que se realiza plenamente em cena, quando cada personagem está em ação. ${ }^{2}$ Modo, portanto, que se realiza plenamente com o espetáculo (ópsis), assumido como parte constituinte do drama, na concepção aristotélica (Idem 49b 31ss e 50a 7ss).

Se quanto aos meios e aos modos há uma semelhança entre tragédia e comédia, se esta é também representação de uma ação completa e com uma certa extensão (Poética 50b 24, 25), há uma diferença quanto ao caráter das personagens. A qualificação de nobre atribuída à ação da tragédia deriva do fato de suas personagens serem elevadas (spoudaîos), enquanto na comédia são baixas (phaûloi)(Idem, 48a 1 e 16).

Apesar de todas as semelhanças entre comédia e tragédia, Aristóteles preferiu estudar esta em paralelo com a epopéia. Segundo Dupont-Roc e Lallot (1980: 178, n. 1), tal preferência faz firmarse a preponderância do elemento ético - o caráter elevado das personagens - sobre o formal $-\mathrm{o}$ drama.

A escolha do paralelo tragédia-epopéia, no entanto, estudada no contexto da Poética, em particular de seu Capítulo 26, firma-se em ponderações estéticas. É verdade que Aristóteles insere no âmbito da estética críticas que beiram a ética: a relação representação menos vulgar-público melhor; a vulgaridade da pantomima; o exagero da expressão corporal ou de movimentos para compensar a inferioridade artística e atingir ao vulgo; atores representando papéis femininos que expressam comportamento indigno de uma mulher livre (não escrava) (Poética, 61b 27ss; 61a 4-9).

Essas críticas não impedem que para responder a

(2) Cf. Poética 48a 23: energoûntas acrescentado a práttontas: em ação agindo.
"Qual a melhor, a representação épica ou a trágica poderia ser uma questão intrigante" (21b 26)

os argumentos decisivos sejam estéticos: a tragédia tem os mesmos recursos que a epopéia; desta pode até empregar o metro; além disso tem a música e o espetáculo; é favorecida pela extensão e pela unidade da ação; pode atingir sua finalidade sem recorrer à expressão corporal, apenas com a leitura, que também faz perceber as qualidades miméticas (Idem 62a 14ss).

Entre esses argumentos encontram-se, de certo modo, características que de novo aproximam a tragédia da comédia: a música e o espetáculo.

Entretanto, acaso se pode dizer que, sem expressão corporal, com a leitura, a comédia revela sua qualidade, atinge seus fins? Que na leitura percebe-se com clareza todas as marcas de representatividade, tanto quanto em cena?

Pode-se responder a essas questões de modo afirmativo: sim, em termos.

Sabemos que o texto das tragédias gregas é farto de informações cênicas, pois as personagens dizem em palavras o que realizam no palco. Contudo, a comédia parece não se guiar por esse mesmo princípio. Estudos sobre a cena de Aristófanes mostram que os textos das comédias são muitas vezes lacunares quanto a esse tipo de informação. Poe (2000: 288-295) lista dezenas de passagens em que movimentos do ator ou elementos do espetáculo não estão indicados no texto, ou são mencionados um bom tempo depois de terem sido vistos pelos espectadores. Desse conjunto destacamos, como exemplo, a conhecida passagem de Nuvens (1102-1104) em que o Justo, ao ser vencido pelo Injusto, declara:

"Fomos vencidos. Ó prostituídos! Pelos deuses, recebam o meu manto, que eu passo para o seu lado". ${ }^{3}$

De fato, não se informa com clareza a quem o Justo entrega o manto; a Estrepsíades e Fidípides? Ao Injusto? Que movimento corresponderia a "eu passo para o seu lado"? Entraria na casa de Sócrates? Iria misturar-se à platéia de "esculhambados"? São questões que permanecem pendentes

(3) Trad. de Gilda Maria Reale Starzynski (1967: 201). 
após a leitura, mas que precisam de definição quando o texto passa a compor o espetáculo.

Contudo, com a orientação de outro filósofo, é possível fazer uma leitura das comédias de Aristófanes que delas revela importantes aspectos Trata-se da abordagem do texto teatral proposta por Etienne Souriau (1993) em As duzentas mil situações dramáticas

Segundo esse estudo, a ação - o drama - de uma peça de teatro se compõe de situações dramáticas. Estas são constituídas por um sistema de forças, ou seja, por funções dramatúrgicas (Souriau 1993: 38-39). Há seis funções dramatúrgicas (Souriau 1993: 60ss): a Força temática orientada, o Representante do bem desejado, o Obtentor do bem, o Oponente, o Árbitro, o Adjuvante.

A Força temática orientada é a função que gera toda situação dramática; expressa o desejo de algo, orienta-se para alguma coisa, para obtê-la no caso da ambição -, ou para evitá-la - no caso do temor. Essa função estabelece o tema da peça, como explicita o termo "temático" em seu nome. O Representante do bem desejado é a função para a qual se orienta a Força temática; o Obtentor do bem, a função para a qual vai o bem desejado pela Força temática; o Oponente, a função que se opõe à Força temática; não haveria drama - ação - se à Força temática orientada não se opusesse algum obstáculo. O Árbitro é a função que tem o poder de conceder ou de recusar o bem, exprime a força que decide da atribuição do bem; o Adjuvante, a função que reforça outra função, assume um papel de co-interessado, cúmplice ou de auxílio e salvador, resultando em duplicação da função que reforça. Esse sistema de forças, encarnadas nas personagens, está em geral presente no microcosmo, - no espaço cênico - que deve sustentar e produzir a reconstituição do universo da obra - o macrocosmo teatral (Souriau 1993: 18).

O microcosmo sustenta o macrocosmo, sendo que o universo da obra deve ultrapassar o universo cênico, para que "haja verdadeiramente teatro" (Souriau 1993: 20); é fundamental a relação entre o "cosmos da obra e seu pequeno núcleo estelar de personagens" (Souriau 1993: 25); de um lado há o mundo, de outro lado um núcleo, ligados de tal modo que "nada acontece num que não tenha resposta no outro"; trata-se da "relação estelar e interestrutural do microcosmo e do macrocosmo teatral (Souriau 1993: 24). Dessa relação macrocosmo-microcosmo depende a avaliação estética; tal relação é determinante do valor da peça, de seu ingresso no âmbito das obras universais, daquelas que têm valor em qualquer espaço e tempo.

Essa abordagem permite, então, à simples leitura das peças, a percepção de temas em situações dramáticas que remetem a valores para além da ação nas circunstâncias de tempo e de lugar demarcadas no espaço cênico. Assim, Diceópolis (Acarnianos), Trigeu (APaz), Lisístrata (Lisistrata), encarnam a função de Força temática orientada, que expressa o desejo de paz. Este bem desejado não é algo circunscrito a Atenas daquele momento, nem à Grécia, como se apenas esta fosse o Obtentor do bem. Trata-se da Paz perseguida pelo homem no mundo, no macrocosmo. E o recurso de que Aristófanes se vale para estender para além de seu espaço-tempo esse bem desejado é o modo como atribui nomes aos heróis nem Diceópolis, nem Trigeu, nem Lisístrata são nomes próprios convencionais em circulação no séc. V a.C. ${ }^{4}$ Ao contrário, são forjados pelo poeta de forma a imprimir neles um programa de ação: Diceópolis é a "cidade justa", Trigeu é "o vindimador", Lisístrata é "a que dissolve os exércitos". Aliás, o nome Lisístrata sugere que Aristófanes se recusava em adotar para seus heróis nomes próprios conhecidos de sua época: à sua disposição havia um quase-sinônimo, Lisímaca ("a que dissolve os combates"), muito provavelmente nome da sacerdotiza de Atena Polias. Mas Dover (1972: 152 , n.2) tem razão em supor que Aristófanes "deliberadamente o evitou e forjou 'Lisístrata' como o mais próximo que ele poderia conseguir". Tal singularidade anula qualquer tentativa de eventual identificação da heroína com esta ou aquela mulher ateniense. Em seu estudo sobre os nomes próprios em Aristófanes, Olson (1992: 306307) observa que, enquanto os tragediógrafos mencionam os nomes dos heróis tão logo surgem em cena, Aristófanes só identifica os seus pelo nome quando considera dramaticamente necessário ou conveniente. Por exemplo, o nome do herói de

(4) Edmunds (1980: 1, n.2) observa que "Diceópolis" não é um nome composto por Aristófanes, pois está documentado em inscrições, mas não informa a data da inscrição. Os dicionários, contudo, citam dikaiópolis como adjetivo, encontrado em Píndaro, e como nome próprio da personagem de Acarnianos. 
Acarnianos só será divulgado no v. 406, quando praticamente um terço da peça já havia transcorrido. ${ }^{5}$ Interpretamos esse adiamento da identificação dos heróis como uma estratégia de ampliação significativa: até a individuação da personagem por meio de um nome próprio, o herói de Aristófanes é um cidadão anônimo, caracterizado por sonhos utópicos e audácia em realizá-los.

Essa relação microcosmo-macrocosmo também se produz nas outras comédias, mesmo quando se restringem ao âmbito da política interna ou da religião e da cultura. ${ }^{6}$

Em Cavaleiros, os servidores de Demos (o povo ateniense) desejam livrar a cidade de Cleão, o demagogo, fazendo com que o próprio povo não se deixe enganar por tal tipo de bajulador. $\mathrm{O}$ ataque a Cleão está presente também na crítica ao judiciário de Vespas, em que se lamentam a mentalidade e os costumes do povo ateniense sob influência do demagogo. Em Nuvens, encontra-se a condenação dos sofistas - Sócrates incluído entre eles -, que prejudicam a formação da juventude. Em Tesmofórias e Rãs faz-se a crítica das personagens femininas de Eurípides, a busca do retorno aos valores da tragédia de Ésquilo, na formação dos heróis da cidade. Em Aves, há o desejo de evitar as misérias de Atenas e a busca de uma nova Pólis, onde houvesse paz e tudo de bom que desta decorre. A comunidade de bens e de mulheres notada em Assembléia de Mulheres e a redistribuição das riquezas propugnada em Pluto levam as buscas para o âmbito do social e das relações familiares.

Por mais que Aristófanes tenha feito em suas peças a representação de personalidades de sua época - Cleão, Sócrates, Eurípides -, de instituições, como o judiciário no contexto da política ateniense, e de minorias - mulheres e pobres da cidade - a força temática de cada peça se orienta para um bem desejado que universaliza o drama. Orienta-se para obter o bem da paz, da consciência política, da verdadeira justiça, da

(5) Olson (1992: 307) cita, como exceções a essa regra, Lisístrata e, em Rãs, Dioniso.

(6) Em Gilda Maria Reale Starzynski (1967: 11), encontra-se a seguinte classificação: I Comédias políticas - a) política externa (Acarnianos, Paz, Lisistrata); b) política interna (Cavaleiros, Vespas); II Comédias de crítica da vida intelectual (Nuvens, Tesmofórias, Rãs); III Comédias de fuga, Alegorias (Aves, Assembléia das Mulheres, Pluto). educação, da produção artístico-literária, da eqüidade. APólis está no espaço cênico, mas esse microcosmo reconstitui o macrocosmo da peça, e, assim, representa os bens desejados pelo homem, no mundo, em qualquer tempo.

A leitura das comédias, portanto, permite, analisando as situações dramáticas, detectar grandes temas universais. Deve-se reconhecer, no entanto, que isso constitui apenas uma parte da "qualidade" da comédia. Acaso essa leitura é capaz de suscitar o riso, o prazer próprio da comédia? permita-nos Aristóteles imitá-lo.

É preciso perguntar-se se é possível rir lendo os recursos cômicos

É muito provável que seja, quando se trata de ardis, de mal-entendidos, de patético ridículo. Qualquer platéia ri com facilidade diante da torturante frustração experimentada em Lisistrata por Cinésias, vítima do engodo de Mirrina, sua esposa; ou dos hilariantes mal-entendidos de Estrepsíades, em Nuvens, diante do empenho de Sócrates em transmitir-lhe conhecimentos sobre gêneros, medidas e ritmos; ou, ainda, quando na cena final de Acarnianos, Lâmaco, a corporificação dos perigos e prejuizos da guerra, entra ferido e carregado, proferindo trágicos lamentos enquanto Diceópolis, bêbado, adentra a cena amparado por duas mulheres nuas, usufruindo os benefícios de sua opção pela paz.

Mas há as paródias, as citações trágicas encaixadas no linguajar cômico, de afetação retórica, o uso cômico dos diferentes registros de linguagem. Para alcançar o efeito cômico desses recursos, o leitor precisa estar atento a peculiaridades da linguagem de Atenas da época, na família e na ágora, de camponeses, de sofistas, de poetas; estar atento aos dialetos, à fala de estrangeiros, aos trocadilhos, às palavras novas, etc... Além disso, estar atento ao que muitas vezes é co-responsável pelo cômico da linguagem: a expressão corporal (gesto, marcação), e os efeitos sonoros não articulados, a aparência exterior dos atores (indumentária, por exemplo), o aspecto do espaço cênico, com seus acessórios e cenários, tudo acrescido do tom em que o texto deve ser pronunciado (Kowzan 1997).

É possível que uma leitura atenta a tantos recursos, em vez de suscitar o riso, provoque o tédio. O riso jamais eclodirá espontâneo após uma leitura interrompida por incontáveis idas-e-vindas do texto dramático às preciosas notas de rodapé 
elucidativas de referências obscuras para o leitor moderno.

Essa, no entanto, é a leitura a que não pode se furtar o encenador, para que tudo o que constitui recurso cômico suscite o riso do público.

Acresce que a leitura do encenador obedece a uma exigência que é do teatro não contemporâneo: com um discurso criado para um determinado público, atingir um outro público, de outra época, com outras preocupações, de outra cultura, em outro espaço teatral (Ubersfeld 1996: 199). É sua tarefa identificar as relações temáticas subjacentes a certos expedientes cômicos a fim de poder encontrar, em seu tempo, substitutos equivalentes. Em alguns casos, a tarefa não parece tão penosa. Tomemos de Acarnianos um exemplo. Acena dos padrinhos que vêm ao mercado de Diceópolis solicitar-lhe, em nome da noiva, uma porção da trégua-vinho, com a qual ela pretende impedir que o noivo atenda à convocação para a guerra, ganha em força cômica graças ao "alabastro" que a madrinha tem nas mãos para recolher a porção. Sabendo-se que o alabastro era um recipiente de formato cilíndrico, alongado, usado para armazenar perfumes, é possível deduzir-se a riqueza das relações semânticas tecidas em cena: os prazeres de uma noite nupcial ameaçados pelos deveres militares, a iniciativa feminina para anular tal ameaça, o poder conjugado do vinho (a trégua) e do perfume, como estimulantes do desejo sexual, poder referido em cena no momento em que Diceópolis verte uma porção da trégua no interior do alabastro, cujo formato fálico é clara alusão ao órgão sexual masculino tumefacto. O que se tem aí, em resumo, é a parceria de Dioniso e de Afrodite contra a força de Ares. Ora, numa representação o encenador terá de recorrer a algum objeto cujo formato colabore na construção das mesmas redes de significados.

A leitura do encenador, então, faz o discurso do autor adquirir sentido, atingir seus fins na área de atuação, no confronto atores-espectadores. A situação dramática, com todos os recursos cômicos, revitalizando-se com o diálogo entre autor e encenador, adquire todo seu sentido e, assim, suscita o prazer que lhe é próprio, o de provocar o riso, no âmbito da encenação.

Filósofos e historiadores, educadores e sociólogos, estudiosos de literatura e de estética teatral, helenistas ou não, podem usufruir da leitura das comédias de Aristófanes e até contribuir para que suas análises, reflexões, descobertas sirvam de subsídio para o encenador. Cabe a este, no entanto, com os atores e com todos os técnicos das artes cênicas, conseguir os aplausos do público que, certamente, ocorrerão na medida do riso suscitado pela peça

Afirma Hegel (1964: 643) que o drama necessita de "ação visível" e de "movente vivacidade", e para tanto julga que seria uma grande contribuição que as peças de teatro não fossem impressas. A peça de teatro "pertenceria em manuscrito ao repertório teatral, seus papéis não seriam demasiadas vezes copiados para não entrarem em circulação".

Talvez não seja obrigatório ser tão radical. Basta que se reconheça que só em cena o discurso teatral atinge seus fins. As comédias de Aristófanes não escapam dessa exigência. Talvez justamente na exigência da encenação esteja todo seu valor estético.

MALHADAS, D.; DEZOTTI, M.C.C. Reading Aristophanes? Rev. do Museu de Arqueologia e Etnologia, São Paulo, 14: 3-8, 2004.

ABSTRACT: The purpose of this essay is to discuss, based on Aristotle's Poetics and studies of semiology of theatre, the possibility of reading old comedy. The aim is to answer this question: can aristophanic comedy, like tragedy, produce its effect without action, by mere reading? The analyses suggest that the power of old comedy depends on the performance.

UNITERMS: Aristophanes - Comedy reading - Performance. 


\section{Referências bibliográficas}

\author{
ARISTOTE \\ 1980 La Poétique. Texte, traduction et notes par R. \\ Dupont-Roc et J. Lallot. Paris: Éditions du Seuil.

Teatral. Trad. Luiz Arthur Nunes e outros. Porto Alegre, Globo: 57-83

OLSON, S.D.

1992 Names and naming in Aristophanes. Classical Quarterly, 42 (ii): 304-319.

POE, J.P.

2000 Multiplicity, discontinuity, and visual meaning in aristophanic comedy. Rheinisches Museum für Philologie, 143 (3-4): 256-295.

SOURIAU, E.

1993 As duzentas mil situações dramáticas Trad. Maria Lúcia Pereira. São Paulo: Ática.

STARZYNSKI, G.M.R.

1967 Aristófanes - As Nuvens. São Paulo: Difusão Européia do Livro.

UBERSFELD, A

1996 Lire le théâtre I. Paris: Belin. 